\title{
Safety Assessment in Road Construction Work System Based on Group AHP-PCA
}

\author{
Xianyong Zhang, ${ }^{1}$ Shifeng Huang, ${ }^{1}$ Shenjun Yang, ${ }^{2}$ Renfang Tu, ${ }^{3}$ and Lianghai Jin $\mathbb{D}^{4}$ \\ ${ }^{1}$ School of Civil Engineering and Mechanic, Huazhong University of Science and Technology, Wuhan, Hubei 430074, China \\ ${ }^{2}$ Sinopec Marketing South China, Guangzhou, Guangdong 510000, China \\ ${ }^{3}$ School of Artificial Intelligence \& Automation, Huazhong University of Science and Technology, Wuhan, Hubei 430074, China \\ ${ }^{4}$ Hubei Key Laboratory of Construction and Management in Hydropower Engineering, China Three Gorges University, \\ Yichang 443002, China
}

Correspondence should be addressed to Lianghai Jin; jinlianghai@ctgu.edu.cn

Received 14 October 2019; Revised 29 December 2019; Accepted 24 January 2020; Published 4 March 2020

Academic Editor: Giuseppe D’Aniello

Copyright (c) 2020 Xianyong Zhang et al. This is an open access article distributed under the Creative Commons Attribution License, which permits unrestricted use, distribution, and reproduction in any medium, provided the original work is properly cited.

\begin{abstract}
The effectiveness and the safety of road construction depend on many factors that pose the greatest risk to system safety. The aim of this study is to conduct a comprehensive assessment for these risk factors to contribute to the safety performance of road construction. To achieve this goal, this study constructs a hierarchical safety assessment framework comprising comprehensive risk indicators according to rich work experience and a relevant literature review and then proposes a group AHP-PCA (group analytic hierarchy process-principal component analysis) to calculate the weights of relevant risk factors. The important rankings of a case study using GAHP-PCA show that professional skill, safety education, and work attitude are the most important factors, which are consistent with the experience and knowledge of road construction safety management. The results also demonstrate that judgment dispersion naturally existing in classical AHP can be effectively reduced when combined with PCA, which is the innovation point of the method given in this article.
\end{abstract}

\section{Introduction}

Many severe accidents resulting in workers' injuries or even deaths occur during the construction process, making the construction industry one of the most dangerous industries [1]. In a specific road construction, there may exist many hazardous zones [2], and road workers face more risks threatening their lives than in any other construction industry [3]. A particular feature of road-construction projects is that each construction site represents a unique workplace, which means different site characteristics are likely to lead to corresponding disasters [4]. Generally speaking, the process of risk management includes different defined risks, which need to be assessed and ranked [5]. Thus, various risk factors that may be encountered in road construction, such as management-related risk factors [6-9], environment-related risk factors $[6,8,10-13]$, and human-related risk factors
$[6,9,13,15]$, should be taken into consideration and assessed comprehensively.

Several studies have been carried out to evaluate and mitigate risks, aiming to provide a safe construction environment. Ning et al. [16] presented a quantitative assessment model to analyze the displacement of different facilities and environmental concerns before construction to get the optimal choice for site managers. Fung et al. [17] presented a program using Excel to conduct a systematic occupational risk assessment for different work trades. Lingard et al. [18] revealed the complex relationship between safety management and injury rate by researching a large Australian infrastructure project. Farooq et al. [19] developed and applied an adjustment factor for optimized risk measurement to improve the risk quantification in construction projects. Zhou et al. [20] used a hybrid assessment approach to analyze the influence of human factors on construction 
accidents. Although this prior research analyzed risk factors in construction sites from different viewpoints and developed corresponding strategies, they did not specifically consider risk assessment for road construction. In addition, they do not have a sufficiently comprehensive risk index system. Akay et al. [21] adopted fuzzy AHP to assess the six main risk factors and 22 subrisk factors during the forest road's design and construction process and figured out incorrect road alignment, inadequate work safety in the field, and insufficient capital are the most important risk factors. The results do not take into account the opinions of multidisciplinary experts and various stakeholders, making them unreliable and unconvincing.

Road construction projects characteristically have long route lines, on which there may be bridges, tunnels, and other complex ancillary engineering work being undertaken at the same time [22]. Smooth project progress depends on numerous workers, multiple varieties of mechanical equipment, and sufficient materials. All these factors are risk sources during road construction. It is generally accepted that appropriate risk factor analysis must depend on the use of systemic and organizational models [23]. In this paper, the causes of a large number of representative road construction accident cases, including bridges, tunnels, and ordinary road sections, are explored. Classifying and stratifying these causes with respect to relevant theories, indicators that may lead to accidents, and a structured assessment index framework were obtained. To understand the degree of importance of the factors contributing to an accident, an appropriate approach must be taken to quantify their importance. In other words, priority rankings must be calculated.

The analytic hierarchy process (AHP) proposed by Saaty [24] can mathematically model the decision process using a structured methodology. It has a wide range of applications for quantifiable and/or intangible criteria problems [25]. As decision-making usually involves a group of individuals, the traditional AHP has been developed into the group AHP method, so as to aggregate multiple perspectives and to improve accuracy and authority. The method has been widely used in group decision-making, such as using multiple criteria for the selection of software, the most suitable fire protection for steel structures, and assessment of water resource sustainability [26-28].

However, to achieve a result in which all participants can accept the group decision-making, all judgments must be homogeneous and a broad consensus must be reached. This rarely happens in many cases because decision makers tend to have significant differences of opinion (that is, there is "dispersion"). Dispersion arises when group members disagree with each other about particular issues, accounting for violation of Pareto optimality. A common mathematically valid way to solve the problem is to use the geometric mean of experts' judgments as a representative value [29]. But sometimes, the data from different decision makers are so dispersed that they are unwilling to compromise, and the geometric mean is no longer appropriate for aggregating judgments [30]. To deal with this dilemma, Huang et al. [31] adopted "preferential differences" and "preferential ranks" to aggregate different viewpoints, but they did not conduct any dispersion tests to verify their validity. Pedrycz and Song [32] proposed an aggregation method utilizing granular matrices but also did not study dispersion. Another, more general, method is therefore needed to achieve a reasonable aggregation of raw judgments.

Based on the covariance matrix of an original data matrix, principal component analysis (PCA) is a statistical method frequently used for coping with multidimensional data [35]. PCA can be used to calculate the weight vector needed to attain a reasonable linear combination of the raw dataset, the outcome of which is a new variable which can be viewed as an optimal representative of the original data [35]. This method has been used in many fields, such as biology and mining [34, 35, 36]. Because no assumptions are made about variable distributions in PCA, this approach can process any dispersed data. This research used it to aggregate a comparison matrix into a synthesized judgment matrix in AHP, so as to achieve a significant dispersion reduction.

\section{Proposed Method: Group AHP-PCA}

The management and evaluation of safety in road construction are concerned with multiple safety factors. It is therefore a multicriteria decision-making problem, requiring managers to thoroughly understand the degree of importance of all indicators in the index system. Only through this understanding by managers can the best prevention measures be determined and targeted. To achieve this goal, an evaluation index system in a hierarchical structure was established by analyzing 190 road construction accident cases in combination with relevant risk theory. A questionnaire to support a group AHP, which can collect experts' views on the relative importance of these indicators, was then designed. Based on this data, a comparison matrix can be constructed. The weight vector is then derived according to PCA which is used to create a low-dispersion group judgment matrix. Lastly, the local weights of indicators at different levels can be obtained from the AHP group judgment matrix, and global weights can be obtained by multiplying the related local weights. The detailed process is showed in Figure 1.

2.1. Constructing the Evaluation Index System. A rational selection of risk factors is crucial to the results of the final evaluation [38]. The complexity of the causes of accidents requires a thorough investigation of underlying hazards during the road construction process [39]. By analyzing the causes of a large number of accidents according to accidentcausation theories, including the Heinrich domino theory of accident causation, the multiple causation model, management-based theories, and the accident root causes tracing model [40], the mechanisms and patterns of accidents can be determined. This leads to understanding the process of accident occurrence. An investigation of accident reports collected from the safety supervision department was conducted, and a classification of accidents in road construction projects is given in Table 1. As can be seen, the statistics show 


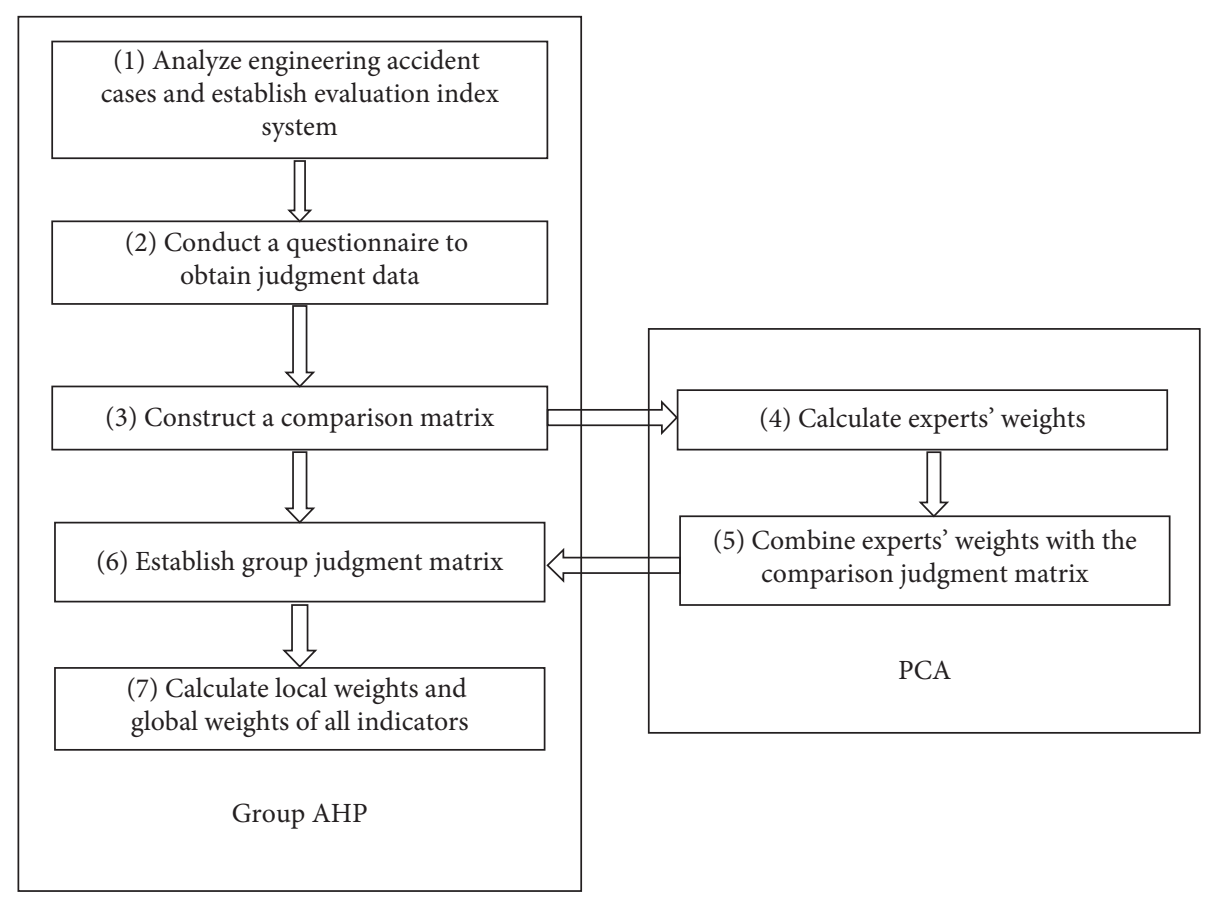

Figure 1: The process of the group AHP-PCA method.

TABLE 1: Type and proportion of statistical accidents.

\begin{tabular}{lcc}
\hline Type & Number & Proportion (\%) \\
\hline Explosion & 9 & 4.52 \\
Vehicle injury & 8 & 4.02 \\
Electric shock & 5 & 2.51 \\
Falling & 35 & 17.59 \\
Fire & 4 & 2.01 \\
Mechanical accident & 20 & 10.05 \\
Leakage & 8 & 4.02 \\
Collapse & 71 & 35.68 \\
Object strike & 33 & 16.58 \\
Others & 6 & 3.02 \\
Sum & 199 & 100 \\
\hline
\end{tabular}

that collapse, falling, and object strike are the most frequent types, accounting for nearly $70 \%$ of the total. This suggests that importance should be attached to monitoring such accidents in road construction engineering projects.

Combining the results of the analysis of road engineering accidents with the risk indicators of previous works $[6-15,41]$, the indicators of the road construction accident risk are divided into 5 criteria and 28 subcriteria according to AHP. These contain all of the risk factors in the analyzed cases and each of them has certain independence. The assessment framework is shown in Figure 2, and a detailed illustration of each indicator is shown in Table2.

2.2. Group AHP Method. Road construction safety assessment relates to complex processes with multiple objective and subjective indicators, as illustrated in Table 1. In this situation, AHP is a particularly appropriate assessment method because it requires that decision makers provide judgments on only two indicators instead of simultaneously on all the indicators. In traditional AHP, the final evaluation result can, however, easily be affected by an individual's academic background and personal bias, making it too subjective [42]. It is preferable for multiple people to play a part in making a decision. The group AHP method was developed to overcome this drawback by synthesizing the judgment of a panel of experts, comprising technically competent and experienced professionals as well as various other stakeholders. Therefore, in this paper, the group AHP (GAHP) method forms the basis for road construction safety assessment. A detailed introduction of AHP and its application in the context of group decision-making are as follows.

The GAHP method breaks the decision-making processes into four steps: problem modelling, pairwise comparisons, priorities derivation, and consistency test [43]. The aim of the first step is to establish a hierarchical assessment framework (Figure 2), with the goal of the decision at the top and criteria and subcriteria in the intermediate and bottom layers, respectively. Experts are then invited to conduct pairwise comparisons of all the elements at the same level (from bottom to top) with respect to the level immediately above. The results of the comparisons are recorded in the form of relative importance numerical values, in relation to a given scale of absolute numbers (Table 3 ). This scale quantifies the verbal qualitative descriptions that express the importance of one element relative to another. A reciprocal matrix (the "comparison matrix") can be derived based on the results of the questionnaire, where the element $a_{i j}^{k}$ means the $k$-th expert judgment value of element $i$ relative to element $j$. Before converting the comparison matrix into a "judgment matrix" (whose eigenvector corresponding to the largest eigenvalue represents the required indicator weight vector), the experts' judgments must be integrated. Usually, 


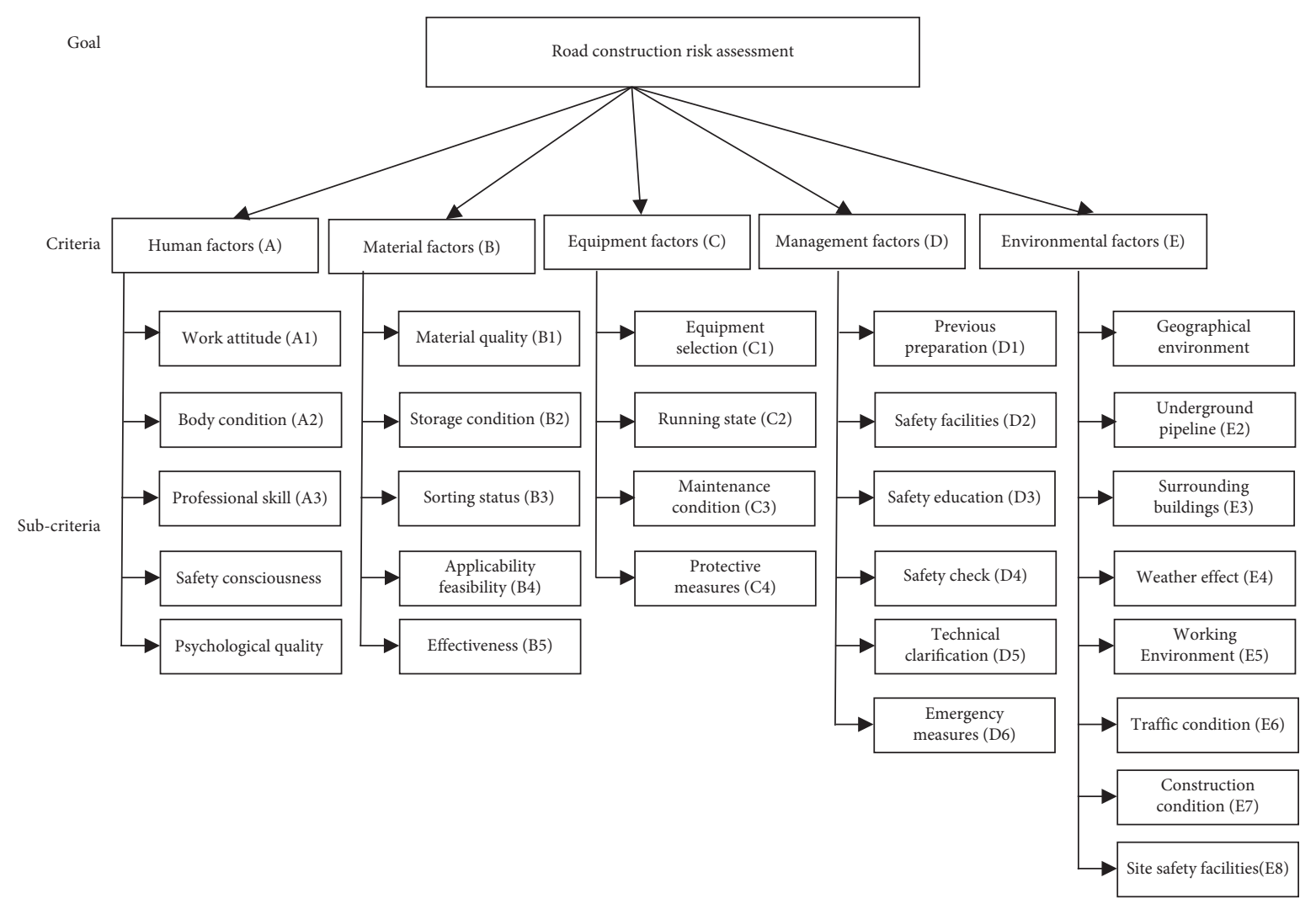

FIGURE 2: Hierarchical risk assessment framework for road construction.

classical AHP calculates the geometric mean (GM) of various experts' judgment values on the same pairwise comparison to provide a consensus value. Finally, a consistency test must be done to ensure the validity of results. That is, for example, when 2 is entered into the $(i, j)$ position in the judgment matrix and 3 entered into the $(j, k)$ position, the entry in $(i, k)$ should be around 6 . This process ensures that the result is not meaningless as a result of a large number of errors. Details on this checking process have been described by Saaty and Basak [44].

2.3. Principal Component Analysis (PCA). PCA is a basic analysis method for multivariate data [46]. For a large amount of variable data, some must have an intensive correlation. That is, some variables carry similar information to others. Therefore, only a selection of the original data is needed for representing the total dataset, a process known as data dimensionality reduction. The principle of dimensionality reduction is that the original data are projected into a new orthogonal coordinate system, the direction of which is oriented by the eigenvector of the covariance matrix of the original data matrix. The new mutually orthogonal variables obtained by projection are called the principal components; the component with the maximum variance is the first principal component, which represents most of information contained in the raw matrix. Generally speaking, a few principal components are enough to preserve the majority of the variance of the original dataset [33]. Thus, the first principal component can be used as an appropriate aggregation of experts' judgments in the context of group decision-making.

2.4. Combination of Group AHP and PCA. As described, AHP typically uses the GM to aggregate individual judgment matrices. But, when judgments are too dispersed, the GM is no longer an appropriate aggregation method. For an extreme example, consider the case where two experts conduct a pairwise comparison for the same pair of indicators, where one person's judgment value is $1 / 9$, whereas the other is 9 . The GM of these two judgment values is 1, suggesting that the two indicators are equally important-an outcome that would be unacceptable to both experts. We therefore intend to replace the GM with the results of PCA in the flowchart when transforming the individual matrix. The experts' weights obtained by PCA are used to create the synthesized matrix and thus to simultaneously reduce dispersion.

To illustrate the procedure of group AHP-PCA, the transformation process between matrices can be shown in Figure 3. The detailed description can be divided into the following steps:

Step 1: use the questionnaire data to establish the comparison matrix

Step 2: take out the upper triangular elements of the comparison matrix in the left-to-right and top-tobottom order to form the individual matrix

Step 3: calculate the first principal component of the individual matrix as the expert personal weight matrix, 
TABLE 2: Examples of indicators used in the assessment framework.

\begin{tabular}{|c|c|}
\hline First-level indicators & Second-level indicators \\
\hline \multirow{5}{*}{ Human factors (A) } & Work attitude (A1) \\
\hline & Body condition (A2) \\
\hline & Professional skill (A3) \\
\hline & Safety consciousness (A4) \\
\hline & Psychological quality (A5) \\
\hline \multirow{5}{*}{ Material factors (B) } & Material quality (B1) \\
\hline & Storage condition (B2) \\
\hline & Sorting status (B3) \\
\hline & $\begin{array}{c}\text { Applicability } \\
\text { feasibility (B4) }\end{array}$ \\
\hline & Effectiveness (B5) \\
\hline \multirow{3}{*}{$\begin{array}{l}\text { Equipment factors } \\
\text { (C) }\end{array}$} & Equipment selection $(\mathrm{C} 1)$ \\
\hline & Running state $(\mathrm{C} 2)$ \\
\hline & $\begin{array}{c}\text { Maintenance } \\
\text { condition (C3) } \\
\text { Protective measures }(\mathrm{C} 4)\end{array}$ \\
\hline
\end{tabular}

$$
\text { Example }
$$

Inactivity, inattention, not satisfied with the status quo, feel being treated unfairly, not following the rules, and not operating equipment as required

Poor health, depression, working long hours, high intensity of work causing poor mental state

Degree of education, years of working, special professional skill level, knowledge of training, operation proficiency

Improper use of safety devices, entering the construction site without safety helmet, noncompliance with defined operational procedures

Keep calm when facing hazardous conditions and resist pressure to remedy or to get out of dilemma

\section{Defective material}

Dangerous goods are not stored according to regulations

Waste materials are not disposed of in time

The material does not meet the requirements of the construction site

Material life cycle, performance, and durability cannot achieve the desired effect or their role cannot be fully played

Poor equipment performance leads to failure to meet construction requirements

Poor equipment quality means it is fault-prone when running, problems with accessories

No regular inspection to detect and resolve failures, no regular maintenance

No safety precautions put in place for the equipment

The construction plan draft in the early stage is not in line with the actual situation, Previous preparation (D1) distribution of resources and labor forces is inappropriate, no rigorous safety system is established, unclear assignment of responsibility and authority

No technical measures are taken to reduce the risk factors, such as occupational disease and unreasonable use of electricity

Management factors

(D)

Safety facilities (D2)

Safety education (D3)

Safety check (D4)

Technical

clarification (D5)

Emergency measures (D6)

Geographical

environment (E1)

Underground

pipeline (E2)

Surrounding

buildings (E3)

Environmental

factors (E)
Weather effect (E4)

Working

environment (E5)

Traffic condition (E6)

Construction

condition (E7)

Site safety facilities (E8)
No regular safety education is organized for workers corresponding their position

No regular inspection of the construction environment and safety facilities

No safe technical disclosure before construction is carried out by management and construction personnel

No reasonable emergency plan for site safety hazard made

Mainly including special soil quality, water quality, and karst cave

Various pipelines laid below ground level, such as gas pipes, sewage pipes, and power pipes

Residential buildings, commercial buildings, and industrial buildings around the site may cause excessive Earth pressure

During the construction process, the rain, snow, and wind may cause safety hazard

Defects in temperature, light intensity, air quality, noise, and so on

Too much traffic will cause the surrounding road to vibrate

The site layout is not appropriate, debris piled up resulting in small working space

The safety devices which contain fine mesh safety vertical net, danger signs, inward and outward signs, and so on are not installed reasonably

TABle 3: The fundamental scale of absolute numbers for AHP (adopted from [45]).

\begin{tabular}{lr}
\hline Numerical values & Verbal gradation \\
\hline 1 & Element $i$ is as important as element $j$ \\
3 & Element $i$ is moderately more important than element $j$ \\
7 & Element $i$ is strongly more important than element $j$ \\
9 & Element $i$ is very strongly more important than element $j$ \\
$2,4,6,8$ & Element $i$ is extremely more important than element $j$ \\
$1,1 / 2, \ldots, 1 / 8,1 / 9$ & The importance of $i$ relative to $j$ is between adjacent judgments \\
\hline
\end{tabular}


1. Comparison matrix. $n$ refers to element numbers, and $m$ refers to expert numbers.

$$
a_{i j}=1 / a_{j i}
$$

2. Individual matrix. Each row denotes one specific pairwise comparison, and each column denotes one specific judge

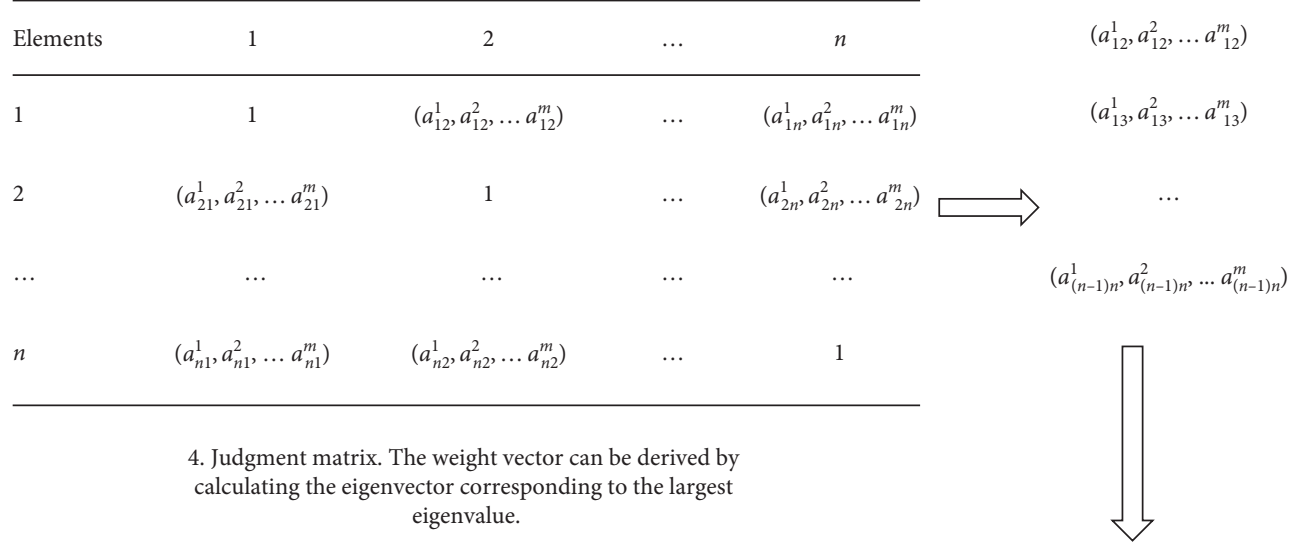

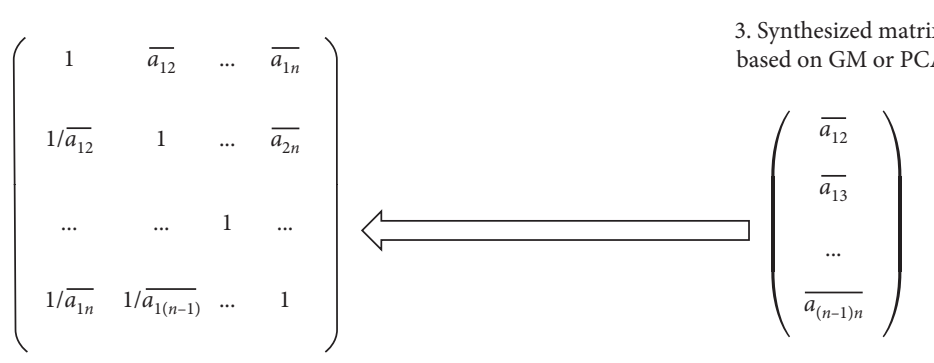

FIgURE 3: Computational flowchart for GAHP.

and then multiply the individual matrix by the weight matrix to obtain the synthesized matrix

Step 4: arrange the elements of the synthesized matrix into the judgment matrix in the order that they were extracted, and the elements below the main diagonal line are complemented according to the reciprocal principle

Step 5: calculate the weight vector of the risk indicators using the judgment matrix according to the classical AHP

\section{Case Study}

3.1. Project Profile. The case study is a proposed urban secondary road in Zunyi, Jiangxi Province, China, which contains culverts and bridges along its route. The total length is $9.5 \mathrm{~km}$, and the construction period is 2 years. The landforms along the line are diverse, and geology is complex. Some of the notable features of the project include a complex engineering environment, difficult personnel management, and diverse construction equipment and materials. It is therefore necessary to carry out a safety assessment to determine the most unfavorable risk factors that might result in disasters and to take corresponding countermeasures in advance to ensure the smooth and safe implementation of the project.
3.2. Questionnaire Survey. A questionnaire method was used to collect the data needed for the application of the GAHP-PCA method. The questionnaire has six parts, each consisting of pairwise comparisons between the indicators of one criteria item and the five subcriteria items. The first part is shown in Table 4. Five experts involved in the project were invited to fill in the questionnaire. Their profiles are shown in Table 5. All questionnaires received positive responses before the deadline, and the results are considered to be representative because the expert's knowledge background basically covers all aspects of the evaluation system.

3.3. Application of the GAHP-PCA Method. Taking the five indicators at the criteria level as an example (human factors (A), material factors (B), equipment factors (C), management factors (D), and environmental factors (E)), the detailed process of the proposed method is described as follows:where $\omega_{i}$ is the local priority of a subcriteria indicator, $\omega_{p}$ is the weight of the criteria indicator, and $\omega_{g}$ represents the corresponding global priority.

Step 1: construct the comparison matrix. The comparison matrix is constructed using the questionnaire data. For the criteria level, the target matrix including 
TABle 4: Part of the questionnaire.

You are invited to participate in this anonymous questionnaire survey. The survey data will be used to determine indicators weights and importance priorities of road construction safety assessment. Please tick your option from the list based on your experience. Thank you for your cooperation!

\section{Personal information}

1. What is your major occupation? (a). Professor in construct safety; (b). Manager in material and equipment;

(c). Manager in construction site; (d). Professor in geological survey; (e) construction worker; (f). Other

2. How long have you been in your job? (a). 1-10 years; (b). 11-20 years; (c) 21-30 years; (d). 31 years and above

3. What is your highest educational qualification? (a). Doctor; (b). Master; (c). Bachelor; (d). Other

\section{Questionnaire}

Part 1 there are five indicators of the criteria level in the road construction assessment system below. Pairwise comparisons with respect to goal level (the immediately upper level of the criteria) are conducted one by one to obtain their priorities importance. Please give quantitative judgment according to the qualitative description in the fundamental scale of absolute numbers table.

1. Human factors and material factors:

$1 / 91 / 81 / 71 / 61 / 51 / 41 / 31 / 2123456789$

2. Human factors and equipment factors:

$1 / 91 / 81 / 71 / 61 / 51 / 41 / 31 / 2123456789$

3. Human factors and management factors:

$1 / 91 / 81 / 71 / 61 / 51 / 41 / 31 / 2123456789$

4. Human factors and environment factors:

$1 / 91 / 81 / 7$ 1/6 1/5 1/4 1/3 1/2 123456789

5. Material factors and equipment factors:

1/9 1/8 1/7 1/6 1/5 1/4 1/3 1/2123456789

6. Material factors and management factors:

1/9 1/8 1/7 1/6 1/5 1/4 1/3 1/2123456789

7. Material factors and environment factors:

1/9 1/8 1/7 1/6 1/5 1/4 1/3 1/2123456789

8. equipment factors and management factors:

1/9 1/8 1/7 1/6 1/5 1/4 1/3 1/2123456789

9. equipment factors and environment factors:

$1 / 91 / 81 / 71 / 61 / 51 / 41 / 31 / 2123456789$

10. Management factors and environment factors:

$1 / 91 / 81 / 71 / 61 / 51 / 41 / 31 / 2123456789$

Table 5: Profiles of experts involved in the project.

\begin{tabular}{lccc}
\hline Number & Working seniority & Occupation & Education \\
\hline 1 & 23 & Manager in material and equipment & Doctor \\
2 & 15 & Professor in construction safety & Doctor \\
3 & 17 & Manager in construction site & Master \\
4 & 28 & Professor in geological survey & Master \\
5 & 10 & Construction worker & Bachelor \\
\hline
\end{tabular}

TABLE 6: Comparison matrix between indicators at the criteria level with respect to the goal level.

\begin{tabular}{lccccc}
\hline & $A$ & $B$ & $C$ & $D$ & $E$ \\
\hline$A$ & 1 & $(3,3,1,3,7)$ & $(7,7,3,1,3)$ & $(1 / 3,1 / 5,1 / 3,3,7)$ & $(3,3,5,1,7)$ \\
$B$ & 1 & $(3,1 / 3,1,1 / 3,1 / 3)$ & $(1 / 3,1 / 3,1 / 5,3,1)$ & $(1,3,3,1 / 3,5)$ \\
$C$ & & 1 & $(1,5,1 / 5,7,3)$ & $(3,3,5,1,1 / 3)$ \\
$D$ & & & 1 & $(1,1 / 5,1 / 3,1 / 5,3)$ \\
$E$ & & & & 1 & 1 \\
\hline
\end{tabular}

the five indicators is shown in Table 6. When an expert's comparison value of $A$ versus $B$ is 3 , the result of $B$ versus $A$ is automatically $1 / 3$; the comparison matrix is therefore a reciprocal matrix.
Step 2: construct the individual matrix, $A$. The elements above the main diagonal line of the comparison matrix are extracted in the left-to-right and top-to-bottom order to form the individual matrix as follows: 


$$
A=\left(\begin{array}{lllll}
3 & 3 & 1 & 3 & 7 \\
7 & 7 & 3 & 1 & 3 \\
\frac{1}{3} & \frac{1}{5} & \frac{1}{3} & 3 & 7 \\
3 & 3 & 5 & 1 & 7 \\
\frac{1}{3} & \frac{1}{3} & \frac{1}{5} & 3 & 1 \\
3 & \frac{1}{3} & 1 & \frac{1}{3} & \frac{1}{3} \\
1 & 3 & 3 & \frac{1}{3} & 5 \\
1 & \frac{1}{5} & \frac{1}{3} & \frac{1}{5} & 3
\end{array}\right),
$$

Step 3: construct the "transform matrix" $A^{\prime}$. The logarithm of each entry in the individual matrix $A$ is calculated, so as to make the numerical values continuous.

Step 4: calculate the expert weight vector $\omega$ according to PCA. The eigenvector corresponding to the largest eigenvalue of the covariance matrix of the transform matrix is verified by Matlab. After normalizing the eigenvector, the weights of all experts can be calculated

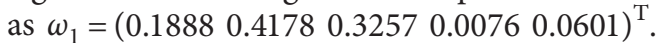

$$
\begin{aligned}
B & =\operatorname{Cov}\left(A^{\prime}\right), \\
B \omega_{1} & =\lambda_{\max } \omega_{1} .
\end{aligned}
$$

Step 5: develop the synthesized matrix. The first principal component $B$ is equal to $A^{\prime} \omega_{1}$. The synthesized comparison values are obtained by using $\exp (B)$; thus, (2.2071 4.97420.2925 3.69700.72190.30662.4723 $\left.\begin{array}{lll}1.2574 & 3.0792 & 0.3766\end{array}\right)^{\mathrm{T}}$.

Step 6: establish the AHP judgment matrix $A^{\prime \prime}$ to calculate the weights of all indicators. The synthesized comparison values are arranged into a judgment matrix in the extracted order, and the elements below the main diagonal line are complemented according to the reciprocal principle. According to AHP, the eigenvector corresponding to the largest eigenvalue of the judgment matrix provides the indicator priority vector for the criteria; thus, $\omega_{p}=(0.29350 .11910 .17140 .26630 .1497)$, $\lambda_{\max }=5.4296$.

$$
A^{\prime \prime}=\left(\begin{array}{cccccc}
1 & 2.2071 & 4.9742 & 0.2925 & 3.6970 \\
\frac{1}{2.2071} & 1 & 0.7219 & 0.3066 & 2.4723 \\
\frac{1}{4.9742} & \frac{1}{0.7219} & 1 & 1.2574 & 3.0792 \\
\frac{1}{0.2925} & \frac{1}{0.3066} & \frac{1}{1.2574} & 1 & 0.3766 \\
\frac{1}{3.6970} & \frac{1}{2.4723} & \frac{1}{3.0792} & \frac{1}{0.3766} & 1
\end{array}\right),
$$

Step 7: consistency test. In group AHP-PCA, consistency should be examined for not only the judgment matrix but also for the comparison matrix for every expert. The continuity strength is measured by the consistency ratio (CR). When the CR is less than 0.1, the result vector is considered to be within an acceptable margin of error and can therefore be adopted. The formula for CR is given by equation (5), where CI is the consistency index and CR is a random index which is shown in Table 7. Thus,

$$
\begin{aligned}
\mathrm{CI} & =\frac{\lambda_{\max }-n}{n-1}, \\
\mathrm{CR} & =\frac{\mathrm{CI}}{\mathrm{RI}},
\end{aligned}
$$

where $n$ is the dimension of the matrix to be checked and $\lambda_{\max }$ is the largest eigenvalue [44]. Taking comparison matrix $A^{\prime \prime}$ as an example, $\mathrm{CI}=0.1074$ and $\mathrm{RI}=1.12$, so $\mathrm{CR}=0.09589<0.1$.

The same calculation procedure is applied to all five subcriteria, with the local weights of the indicators calculated as follows : $\omega_{A}=\left(\begin{array}{llll}0.2235 & 0.1164 & 0.3597\end{array}\right.$ $\left.\begin{array}{ll}0.1579 & 0.1425\end{array}\right)^{\mathrm{T}}, \quad \omega_{B}=\left(\begin{array}{llll}0.3621 & 0.1513 & 0.0702 & 0.2187\end{array}\right.$ $0.1977)^{\mathrm{T}}, \quad \omega_{C}=\left(\begin{array}{llll}0.1587 & 0.2364 & 0.3125 & 0.2924\end{array}\right)^{\mathrm{T}}$,

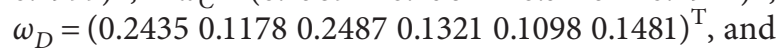

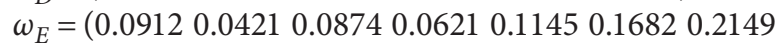
$0.2196)^{\mathrm{T}}$.

Step 8: calculate global importance priorities. The final step is to synthesize the local priorities by multiplying each local weight by the weight of the indicator immediately above it, so as to determine global weights using 
TABLE 7: Random indices from [46].

\begin{tabular}{lcccccccc}
\hline$n$ & 3 & 4 & 5 & 6 & 7 & 8 & 9 & 10 \\
RI & 0.58 & 0.9 & 1.12 & 1.24 & 1.32 & 1.41 & 1.45 & 1.49 \\
\hline
\end{tabular}

$$
\omega_{g}=\omega_{p} \omega_{i}
$$

At the end of this process, the global weights of all of the subcriteria indicators for road construction safety assessment have been obtained and have been ranked. For the sake of comparison, the results calculated from the original AHP are listed in Table 8 together with the results of the group AHP-PCA process. The weights of the five indicators (human factors (A), material factors (B), equipment factors (C), management factors (D), and environmental factors (E)) at the criteria level based on the proposed AHP-PCA method are $0.2935,0.1191,0.1714,0.2663$, and 0.1497 , respectively. The ranking column reveals that the top 5 indicators affecting the safety level of the project are professional skill, safety education, work attitude, previous preparation, and maintenance condition. The lower rankings refer mostly to indicators relating to materials, equipment, and environment.

\section{Results and Discussion}

Table 8 , indicates that the results of the two calculation methods have not changed much overall. Differences just exist in individual risk factors between two methods. For example, at the criteria level, the indicators with the most obvious changes are human factors and management factors, whose priority weights decrease from 0.3330 to 0.2935 and increase from 0.2041 to 0.2663 , respectively. The immediate cause leading to the changes is the transformation of the comparison matrix. As can be seen from Table 6 , the pairwise comparisons $(A, B),(A, D)$, and $(C, D)$ have a large geometric dispersion, which means the result may shift in a certain direction. The root cause for the excessive dispersion in the comparison matrix can be found in Table 5, where the fifth expert is a construction worker whose occupation makes him have a preference for the human factor and rate this far higher than the other factors. Referring back to Table 6, it can be seen that three of his scale judgments are 7 when comparing human factors with material factors, management factors, and environment factors, thus resulting in large dispersion in the individual matrix. Traditional AHP follows the principle that the weight of each expert is equal, regardless of the negative effects because of the differences in experts' knowledge background. In contrast, the improved AHP can adjust the weight of experts to modify the judgment matrix which weakens the preference influence of expert 5 in the group decision-making, and then the above changes of priority weight appear. As can be found, the same changes have occurred at the subcriteria level. The five risk factors that have the greatest impact on the goal layer calculated by the GAHP-PCA method are professional skill (A3), safety education (D3), work attitude (A1), previous preparation (D1), and maintenance condition (C3). Comparatively, the corresponding result based on traditional AHP is professional skill (A3), work attitude (A1), safety consciousness (A4), psychological quality (A5), and protective measures (C4). Obviously, due to the lack of consideration of the differences in the knowledge background of experts, four of the five subcriteria risk factors belong to human factors. In contrast, after the expert weights were corrected with PCA, the priority importance of other risk factors was highlighted, which is more reasonable from practical perspective.

When considering the weight rankings of risk indicators at the criteria level, the results calculated by the two methods are equal. Ranked by values of risk weight from large to small, they are, respectively, human factors, management factors, equipment factors, environmental factors, and material factors. Among these risk factors, the sum of the weights of human and management factors exceeds $50 \%$, which indicates that the safety quality of construction personnel and the completeness of safety management measures have largely determined the safety level of the construction site.

Generally speaking, the more skilled a worker is, the less time it takes him to fulfil tasks while avoiding dangers, and safety education is a management process used by many organizations. The results suggest that professional skill, safety education, and work attitude are considered to be the most significant factors, and most construction companies regularly organize relevant training, so these results match actual experience. In addition, since the project is located on a plain with good geological conditions, environmental factors have little impact on the safety risks. Thus, it makes sense that the highest priority weight of the subindicators related to environmental factors is only 0.0239 .

According to the results of GAHP-PCA, the most important risk factors at the criteria level are human factors and management factors. In similar research conducted by Taher et al. [9] about the critical factors determining construction projects, the results from the AHP approach show that the priority importance ratings are $32.1 \%$ for project manager and employer, $24.1 \%$ for logistics, and $22.3 \%$ for project management, which are basically consistent with the results of this study. Additionally, Janackovic et al. [6] also adopted fussy AHP to rank risk indicators during road construction process, and weight rankings of organizational factors and human factors were finally shown to be $1^{\text {st }}$ and $3^{\text {rd }}$, respectively. Kirytopoulos et al. [15] acknowledged that human-related risk factors have a great influence on safety level of road tunnels construction and thus conducted a special risk analysis for human factors based on human reliability analysis. It is worth noting that environment factors account for low priority in this study because the road is located in the plain, which does not mean that environmental factors are not important in general. Various relevant studies have been published highlighting environment factors [11-13]. Assessment for the subcriteria 
TABLE 8: Road construction safety assessment indicators' final weights and ranking based on group AHP-PCA and traditional GAHP.

\begin{tabular}{|c|c|c|c|c|c|c|c|c|c|}
\hline \multirow{2}{*}{ Criteria } & \multicolumn{2}{|c|}{ Weights } & \multirow{2}{*}{ Subcriteria } & \multicolumn{2}{|c|}{ Local weights } & \multicolumn{2}{|c|}{ Global weights } & \multicolumn{2}{|c|}{ Ranking } \\
\hline & GAHP-PCA & GAHP & & GAHP-PCA & GAHP & GAHP-PCA & GAHP & GAHP-PCA & GAHP \\
\hline \multirow{5}{*}{$\begin{array}{l}\text { Human factors } \\
\text { (A) }\end{array}$} & \multirow{5}{*}{0.2935} & \multirow{5}{*}{0.3330} & Work attitude (A1) & 0.2235 & 0.2341 & 0.0656 & 0.0780 & 3 & 2 \\
\hline & & & Body condition (A2) & 0.1164 & 0.1362 & 0.0342 & 0.0454 & 13 & 10 \\
\hline & & & Professional skill (A3) & 0.3597 & 0.2648 & 0.1056 & 0.0882 & 1 & 1 \\
\hline & & & Safety consciousness (A4) & 0.1579 & 0.1874 & 0.0463 & 0.0624 & 7 & 3 \\
\hline & & & Psychological quality (A5) & 0.1425 & 0.1775 & 0.0418 & 0.0591 & 9 & 4 \\
\hline \multirow{5}{*}{$\begin{array}{l}\text { Material factors } \\
\text { (B) }\end{array}$} & \multirow{5}{*}{0.1191} & \multirow{5}{*}{0.1272} & Material quality (B1) & 0.3621 & 0.3462 & 0.0431 & 0.0440 & 8 & 11 \\
\hline & & & Storage condition (B2) & 0.1513 & 0.1752 & 0.0180 & 0.0223 & 22 & 21 \\
\hline & & & Sorting status (B3) & 0.0702 & 0.1203 & 0.0084 & 0.0153 & 27 & 23 \\
\hline & & & $\begin{array}{l}\text { Applicability feasibility } \\
\text { (B4) }\end{array}$ & 0.2187 & 0.1647 & 0.0260 & 0.0209 & 19 & 22 \\
\hline & & & Effectiveness (B5) & 0.1977 & 0.1936 & 0.0235 & 0.0246 & 21 & 17 \\
\hline \multirow{4}{*}{$\begin{array}{l}\text { Equipment } \\
\text { factors }(C)\end{array}$} & \multirow{4}{*}{0.1714} & \multirow{4}{*}{0.1927} & Equipment selection (C1) & 0.1587 & 0.1462 & 0.0272 & 0.0282 & 18 & 16 \\
\hline & & & Running state (C2) & 0.2364 & 0.2562 & 0.0405 & 0.0494 & 10 & 8 \\
\hline & & & $\begin{array}{c}\text { Maintenance condition } \\
\text { (C3) }\end{array}$ & 0.3125 & 0.2951 & 0.0536 & 0.0569 & 5 & 6 \\
\hline & & & Protective measures $(\mathrm{C} 4)$ & 0.2924 & 0.3066 & 0.0501 & 0.0591 & 6 & 5 \\
\hline \multirow{6}{*}{$\begin{array}{l}\text { Management } \\
\text { factors (D) }\end{array}$} & \multirow{6}{*}{0.2663} & \multirow{6}{*}{0.2041} & Previous preparation (D1) & 0.2435 & 0.2621 & 0.0648 & 0.0535 & 4 & 7 \\
\hline & & & Safety facilities (D2) & 0.1178 & 0.1124 & 0.0314 & 0.0229 & 16 & 20 \\
\hline & & & Safety education (D3) & 0.2487 & 0.2351 & 0.0662 & 0.0480 & 2 & 9 \\
\hline & & & Safety check (D4) & 0.1321 & 0.1531 & 0.0352 & 0.0312 & 12 & 13 \\
\hline & & & Technical clarification (D5) & 0.1098 & 0.0543 & 0.0292 & 0.0111 & 17 & 25 \\
\hline & & & $\begin{array}{c}\text { Emergency measures } \\
\text { (D6) }\end{array}$ & 0.1481 & 0.1830 & 0.0394 & 0.0374 & 11 & 12 \\
\hline \multirow{8}{*}{$\begin{array}{l}\text { Environmental } \\
\text { factors }(E)\end{array}$} & \multirow{8}{*}{0.1497} & \multirow{8}{*}{0.1429} & $\begin{array}{l}\text { Geographical environment } \\
\text { (E1) }\end{array}$ & 0.0912 & 0.0812 & 0.0137 & 0.0116 & 24 & 24 \\
\hline & & & Underground pipeline (E2) & 0.0421 & 0.0641 & 0.0063 & 0.0092 & 28 & 26 \\
\hline & & & Surrounding buildings (E3) & 0.0874 & 0.0521 & 0.0131 & 0.0074 & 25 & 28 \\
\hline & & & Weather effect (E4) & 0.0621 & 0.0532 & 0.0093 & 0.0076 & 26 & 27 \\
\hline & & & Working environment (E5) & 0.1145 & 0.2140 & 0.0171 & 0.0306 & 23 & 14 \\
\hline & & & Traffic condition (E6) & 0.1682 & 0.1632 & 0.0252 & 0.0233 & 20 & 19 \\
\hline & & & $\begin{array}{l}\text { Construction condition } \\
\text { (E7) }\end{array}$ & 0.2149 & 0.1674 & 0.0322 & 0.0239 & 15 & 18 \\
\hline & & & Site safety facilities (E8) & 0.2196 & 0.2048 & 0.0329 & 0.0293 & 14 & 15 \\
\hline
\end{tabular}

level factors with respect to goal level showed that professional skill (A3), safety education (D3), and work attitude (A1) are the most important factors. Consistent with this finding, Abdelhamid and Everett [45] emphasized the need to consider worker training, worker attitude, and management procedures when coping with occupational accidents.

From the above analysis, we can conclude that GAHPPCA is capable of retaining the important information about risk while reducing the dispersion of group judgments, and the method can be used effectively to assess the risks of road construction.

\section{Consistency Test}

To verify the validity of the proposed method, that is, when PCA is used to calculate the weighted geometric mean, the dispersion of the group judgment data is indeed reduced. The geometric dispersion of GAHP-GM and GAHP-PCA as described by Saaty and Vargas [30] was calculated and compared. Here, $d_{g}$ and $d_{p}$ are defined as the dispersion of the GM and the PCA, which is calculated according to the following formula:

$$
S_{G}\left(x_{1}, x_{2}, \ldots, x_{n}\right)=S_{G}\left(x_{[1, n]}, x_{[2, n]}, \ldots, x_{[n, n]}\right)=\left(\frac{\bar{x}_{G}}{\bar{x}_{n_{1}}^{G}}\right)^{2 n_{1} / n},
$$

where $S_{G}$ is the sample geometric dispersion and $\bar{x}_{G}$ represents the corresponding geometric mean. The variables in the sample monotonically increase with their subscripts, i.e., $x_{[i, n]} \leq x_{[j, n]}$, if $i<j, n_{1}$ is a value for which $x_{[k, n]} \leq x_{\left[n_{1}, n\right]}$ for $k=1,2, \ldots n_{1}$, and $\bar{x}_{n_{1}}^{G}$ is the geometric mean belonging to the dataset from $n_{1}$ to $n$.

At the criteria level, $d_{p}=5.326$ and $d_{g}=0.6387$, and $d_{g}$ is much lower than $d_{p}$. To highlight the difference, the results of the remaining five groups of comparisons are shown in Figure 4, where it is clear that the dispersion of group judgments has been significantly lowered, indicating that GAHP-PCA is capable of satisfactorily aggregating individual matrix values where excessive dispersion exists. 


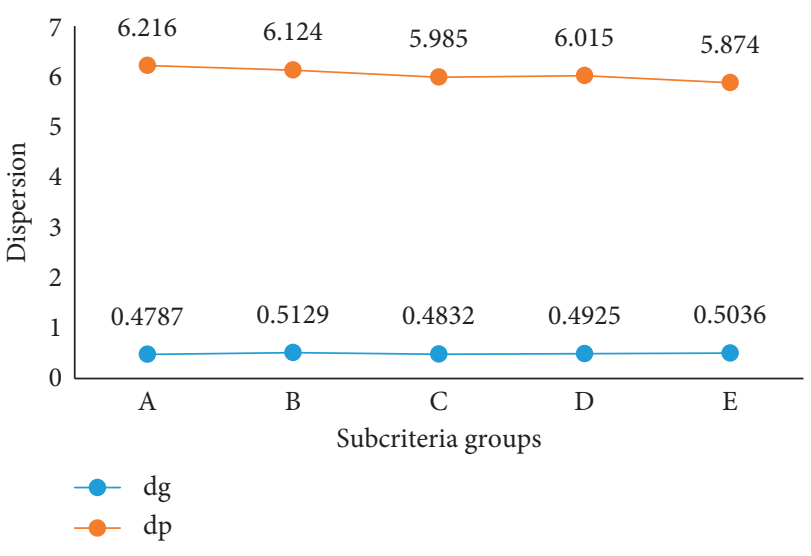

FIgURE 4: Results of dispersion test of subcriteria.

\section{Conclusion}

Based on accident cause theories, this study has summarized the causes of a large number of road safety construction accidents and obtained a range of common risk factors. After screening, a hierarchical index system for road construction risk assessment was established, which consists of 5 criteria and 28 subcriteria risk factors. Then, group AHP was used to conduct pairwise comparisons for all the elements at the same level with respect to the level immediately above in order to calculate the weight rankings of risk factors. Additionally, PCA is used to optimize the weight distributions of experts and to reduce dispersion. The analysis of the case and the consistency tests indicate that the group AHP-PCA is able to synthesize the opinions of multiple experts as well as effectively reduce the dispersion of their judgments.

The index system presented in this paper can help the managers to comprehensively understand multiple aspects of road construction risks, whilst the method is proved capable of properly integrating experts with various levels of knowledge and experiencing and rationally measuring both quantitative and qualitative indicators. The results of the assessment will also enable project managers to compare weight priorities of relevant risk factors and take targeted precautions accordingly.

\section{Data Availability}

The data are available upon the readers' requirement.

\section{Conflicts of Interest}

The authors declare that they have no conflicts of interest.

\section{Acknowledgments}

This research was supported by the National Key Research and Development Program of China (no. 2017YFC0805100) and the Hubei Key Laboratory of Construction and Management in Hydropower Engineering, China Three Gorges University (no. 2019KSD02).

\section{References}

[1] D. Fang and H. Wu, "Development of a safety culture interaction (SCI) model for construction projects," Safety Science, vol. 57, pp. 138-149, 2013.

[2] V. R. Gannapathy, "Risk factors in a road construction site," Proceedings of the World Academy of Science, Engineering and Technology, vol. 46, pp. 640-643, 2008.

[3] R. Y. Ma Li, "Smart construction safety in road repairing works," Procedia Computer Science, vol. 111, pp. 301-307, 2017.

[4] F. J. Forteza, A. Sesé, and J. M. Carretero-Gómez, "CONSRAT. Construction sites risk assessment tool," Safety Science, vol. 89, pp. 338-354, 2016.

[5] R. M. Sum, "Risk management decision making," in Proceedings of the International Symposium on the Analytic Hierarchy Process, Kuala Lumpur, Malaysia, 2013.

[6] G. L. Janackovic, S. M. Savic, and M. S. Stankovic, "Selection and ranking of occupational safety indicators based on fuzzy AHP: a case study in road construction companies," South African Journal of Industrial Engineering, vol. 24, pp. 175-189, 2013.

[7] T. Le, C. H. Caldas, G. E. Gibson, and M. Thole, "Assessing scope and managing risk in the highway project development process," Journal of Construction Engineering and Management, vol. 135, no. 9, pp. 900-910, 2009.

[8] I. Mahamid, "Risk matrix for factors affecting time delay in road construction projects: owners' perspective," Engineering, Construction and Architectural Management, vol. 18, no. 6, pp. 609-617, 2011.

[9] A. Pakseresht and G. Asgari, "Determining the critical success factors in construction projects: AHP approach," Interdisciplinary Journal of Contemporary Research in Business, vol. 4, no. 8, pp. 383-393, 2012.

[10] S. Dione, J. Y. Ruwanpura, and J. P. Hettiaratchi, "Assessing and managing the potential environmental risks of construction projects," Practice Periodical on Structural Design and Construction, vol. 10, no. 4, pp. 260-266, 2005.

[11] S. Gumus, "Constitution of the forest road evaluation form for Turkish forestry," African Journal of Biotechnology, vol. 8, no. 20, 2009.

[12] E. Hayati, "Application of sensitivity analysis in forest road networks planning and assessment," Journal of Agricultural Science and Technology, vol. 15, no. 4, pp. 781-792, 2013.

[13] A. Lunts, "Risk reduction possibilities considering equipment, working environment and human factor in road construction," Safety of Technogenic Environment, vol. 4, pp. 30-36, 2013.

[14] J. L. Zhou, Y. Lei, and Y. Chen, "A hybrid HEART method to estimate human error probabilities in locomotive driving process," Reliability Engineering and System Safety, vol. 188, pp. 80-89, 2019.

[15] K. Kirytopoulos, M. Konstandinidou, Z. Nivolianitou, and K. Kazaras, "Embedding the human factor in road tunnel risk analysis," Process Safety and Environmental Protection, vol. 92, no. 4, pp. 329-337, 2014.

[16] X. Ning, J. Qi, and C. Wu, “A quantitative safety risk assessment model for construction site layout planning," Safety Science, vol. 104, pp. 246-259, 2018.

[17] I. W. H. Fung, V. W. Y. Tam, T. Y. Lo, and L. L. H. Lu, "Developing a risk assessment model for construction safety," International Journal of Project Management, vol. 28, no. 6, pp. 593-600, 2010. 
[18] H. Lingard, M. Hallowell, R. Salas, and P. Pirzadeh, "Leading or lagging? Temporal analysis of safety indicators on a large infrastructure construction project," Safety Science, vol. 91, pp. 206-220, 2017.

[19] M. U. Farooq, M. J. Thaheem, and H. Arshad, "Improving the risk quantification under behavioural tendencies: a tale of construction projects," International Journal of Project Management, vol. 36, no. 3, pp. 414-428, 2018.

[20] J.-L. Zhou, Z.-H. Bai, and Z.-Y. Sun, "A hybrid approach for safety assessment in high-risk hydropower-constructionproject work systems," Safety Science, vol. 64, pp. 163-172, 2014.

[21] A. O. Akay, M. Demir, and M. Akgul, "Assessment of risk factors in forest road design and construction activities with fuzzy analytic hierarchy process approach in Turkey," Environmental Monitoring and Assessment, vol. 190, no. 9, 2018.

[22] J. D'Ignazio, M. Hallowell, and K. Molenaa, Prepared for: NCHRP 20-24 Administration of Highway and Transportation Agencies, NCHRP, Washington, DC, USA, 2011.

[23] J.-L. Zhou and Y. Lei, "Paths between latent and active errors: analysis of 407 railway accidents/incidents' causes in China," Safety Science, vol. 110, pp. 47-58, 2018.

[24] T. L. Saaty, The Analytic Hierarchy Process, McGraw-Hill, New York, NY, USA, 1980.

[25] L. G. Vargas, "An overview of the analytic hierarchy process and its applications," European Journal of Operational Research, vol. 48, no. 1, pp. 2-8, 1990.

[26] V. S. Lai, B. K. Wong, and W. Cheung, "Group decision making in a multiple criteria environment: a case using the AHP in software selection," European Journal of Operational Research, vol. 137, no. 1, pp. 134-144, 2002.

[27] O. U. Akaa, A. Abu, M. Spearpoint, and S. Giovinazzi, "A group-AHP decision analysis for the selection of applied fire protection to steel structures," Fire Safety Journal, vol. 86, pp. 95-105, 2016.

[28] J.-L. Zhou, Q.-Q. Xu, and X.-Y. Zhang, "Water resources and sustainability assessment based on group AHP-PCA method: a case study in the jinsha river basin," Water, vol. 10, no. 12, p. 1880, 2018.

[29] J. Aczél and T. L. Saaty, "Procedures for synthesizing ratio judgements," Journal of Mathematical Psychology, vol. 27, no. 1, pp. 93-102, 1983.

[30] T. L. Saaty and L. G. Vargas, "Dispersion of group judgments," Mathematical and Computer Modelling, vol. 46, no. 7-8, pp. 918-925, 2007.

[31] Y.-S. Huang, J.-T. Liao, and Z.-L. Lin, “A study on aggregation of group decisions," Systems Research and Behavioral Science, vol. 26, no. 4, pp. 445-454, 2009.

[32] W. Pedrycz and M. Song, "Analytic hierarchy process (AHP) in group decision making and its optimization with an allocation of information granularity," IEEE Transactions on Fuzzy Systems, vol. 19, no. 3, pp. 527-539, 2011.

[33] L. L. Palese, "A random version of principal component analysis in data clustering," Computational Biology and Chemistry, vol. 73, pp. 57-64, 2018.

[34] Z.-Y. Sun, J.-L. Zhou, and L.-F. Gan, "Safety assessment in oil drilling work system based on empirical study and Analytic Network Process," Safety Science, vol. 105, pp. 86-97, 2018.

[35] R. Broa and A. K. Smildeab, "Principal component analysis," Analytical Methods, vol. 6, no. 9, pp. 2812-2831, 2014.

[36] A. L. Price, N. J. Patterson, R. M. Plenge, M. E. Weinblatt, N. A. Shadick, and D. Reich, "Principal components analysis corrects for stratification in genome-wide association studies," Nature Genetics, vol. 38, no. 8, pp. 904-909, 2006.
[37] M. O. Smith, P. E. Johnson, and J. B. Adams, "Quantitative determination of mineral types and abundances from reflectance spectra using principal components analysis," Journal of Geophysical Research, vol. 90, no. S02, p. C797, 1985.

[38] A. Suraji, A. R. Duff, and S. J. Peckitt, "Development of causal model of construction accident causation," Journal of Construction Engineering and Management, vol. 127, no. 4, pp. 337-344, 2001.

[39] S. S. Hosseinian and Z. J. Torghabeh, "Major theories OF construction accident causation models: a literature review," International Journal of Advances in Engineering \& Technology, vol. 4, no. 2, pp. 53-66, 2012.

[40] B. A. K. S. Perera, "Risk management in road construction: the case of Sri Lanka," International Journal of Strategic Property Management, vol. 13, no. 2, pp. 87-102, 2009.

[41] J. Guo, M. Zhou, Z. Li, and H. Xie, "Green design assessment of electromechanical products based on group weightedAHP," Enterprise Information Systems, vol. 9, no. 8, pp. 878-899, 2015.

[42] A. Ishizaka and A. Labib, "Review of the main developments in the analytic hierarchy process," Expert Systems with Applications, vol. 38, no. 11, pp. 14336-14345, 2011.

[43] T. L. Saaty, "A scaling method for priorities in hierarchical structures," Journal of Mathematical Psychology, vol. 15, no. 3, pp. 234-281, 1977.

[44] I. Basak and T. Saaty, "Group decision making using the analytic hierarchy process," Mathematical and Computer Modelling, vol. 17, no. 4-5, pp. 101-109, 1993.

[45] T. S. Abdelhamid and J. G. Everett, "Identifying root causes of construction accidents," Journal of Construction Engineering and Management, vol. 126, no. 1, pp. 52-60, 2000.

[46] S. Wold, K. Esbensen, and P. Geladi, "Principal component analysis," Chemometrics and Intelligent Laboratory Systems, vol. 2, no. 1-3, pp. 37-52, 1987. 